\title{
Temperature Effect on Electrical Treeing and Partial Discharge Characteristics of Silicone Rubber-Based Nanocomposites
}

\author{
Mohd Hafizi Ahmad, ${ }^{1}$ Nouruddeen Bashir, ${ }^{1}$ Zolkafle Buntat, ${ }^{1}$ Yanuar Z. Arief, \\ Abdul Azim Abd Jamil, ${ }^{2}$ Mohamed Afendi Mohamed Piah, ${ }^{1}$ Abubakar A. Suleiman, \\ Steve Dodd, ${ }^{3}$ and Nikola Chalashkanov ${ }^{3}$ \\ ${ }^{1}$ Institute of High Voltage and High Current, Faculty of Electrical Engineering, Universiti Teknologi Malaysia, \\ 81310 Johor Bahru, Johor, Malaysia \\ ${ }^{2}$ School of Electronics and Electrical Engineering, Universiti Sains Malaysia, 14300 Nibong Tebal, Penang, Malaysia \\ ${ }^{3}$ Department of Engineering, University of Leicester, Leicester LE1 7RH, UK
}

Correspondence should be addressed to Mohd Hafizi Ahmad; mohdhafizi@fke.utm.my

Received 27 April 2015; Accepted 28 June 2015

Academic Editor: Mircea Chipara

Copyright (C) 2015 Mohd Hafizi Ahmad et al. This is an open access article distributed under the Creative Commons Attribution License, which permits unrestricted use, distribution, and reproduction in any medium, provided the original work is properly cited.

\begin{abstract}
This study investigated electrical treeing and its associated phase-resolved partial discharge (PD) activities in room-temperature, vulcanized silicone rubber/organomontmorillonite nanocomposite sample materials over a range of temperatures in order to assess the effect of temperature on different filler concentrations under AC voltage. The samples were prepared with three levels of nanofiller content: $0 \%$ by weight $(\mathrm{wt}), 1 \%$ by wt, and $3 \%$ by wt. The electrical treeing and PD activities of these samples were investigated at temperatures of $20^{\circ} \mathrm{C}, 40^{\circ} \mathrm{C}$, and $60^{\circ} \mathrm{C}$. The results show that the characteristics of the electrical tree changed with increasing temperature. The tree inception times decreased at $20^{\circ} \mathrm{C}$ due to space charge dynamics, and the tree growth time increased at $40^{\circ} \mathrm{C}$ due to the increase in the number of cross-link network structures caused by the vulcanization process. At $60^{\circ} \mathrm{C}$, more enhanced and reinforced properties of the silicone rubber-based nanocomposite samples occurred. This led to an increase in electrical tree inception time and electrical tree growth time. However, the PD characteristics, particularly the mean phase angle of occurrence of the positive and negative discharge distributions, were insensitive to variations in temperature. This reflects an enhanced stability in the nanocomposite electrical properties compared with the base polymer.
\end{abstract}

\section{Introduction}

Polymeric materials are gaining prominence among utilities as their preferred insulating materials for underground power cables largely due to their high dielectric strength (in $\mathrm{MV} / \mathrm{cm}$ ), very low dielectric losses, high tensile strength, and resistance to electrical degradation [1]. Power cables are subjected to high and continuous voltage as well as mechanical and thermal stresses that induce and accelerate the cable ageing and insulation breakdown. Electrical treeing is one such breakdown phenomenon that occurs in insulation cables, and many researchers have presented studies done on electrical treeing phenomena in insulation cables [2-7]. Treeing occurs inside the dielectric when partial discharges are initiated and progresses under electrical stress through paths that are tree-like. To curb the growth of the electrical tree, many researchers have used microcomposite materials as fillers to enhance the electrical and mechanical strength of the polymer. However, the increasing demand for power and further research has led to the discovery and use of nanocomposite polymers with the addition of nanofillers due to their excellent performance [8-10]. One such nanocomposite that is currently receiving attention as a nanofiller in $\mathrm{HV}$ cable insulation is organomontmorillonite (oMMT). Results from the use of oMMT as a nanofiller in ethylene-vinyl acetate, low-density polyethylene, polyethylene (PE), and epoxy resin have shown improvement in the electrical performance of these insulating materials, such as increases in tree inception voltage, tree initiation time, and time to breakdown and slower tree propagation [11-14]. 
In power cables, silicone rubber ( $\mathrm{SiR})$ is one of the most widely used insulating materials for cable stress cones, jointing, and insulation materials [15-18]. Recently, some electrical treeing studies that investigated the electrical performance of SiR filled with oMMT nanofiller as an insulating material have reported promising results [19-23]. Furthermore, most of the power cables in service operate at temperatures in the range of $50^{\circ} \mathrm{C}$ to $60^{\circ} \mathrm{C}[24,25]$. However, studies carried out on $\mathrm{SiR} / \mathrm{oMMT}$ nanocomposites were limited to those on the effect of filler content on the performance of the insulation at ambient temperature. And thus electrical treeing associated with partial discharge studies on the effect of temperature on SiR/oMMT nanocomposites are lacking. In view of the foregoing, this work presents an investigation on the effect of temperature on electrical treeing and partial discharge characteristics of silicone rubber-based nanocomposite insulation. Findings from this study indicated that temperature and filler concentrations have effect on electrical treeing and partial discharge characteristics of polymeric insulation.

\section{Nanoclay}

Nanoclay belongs to the family of phyllosilicates, which are also known as layered silicates. Nanoclay is classified into four typical groups: smectite, kaolin, chlorite, and illite. Montmorillonite belongs to the smectite group. The layered silicate crystal lattice consists of a two-dimensional, sheetlike structure, where the central octahedral of the alumina sheet or magnesia is placed between two silica tetrahedron sheets. The oxygen ions of the octahedral sheet are shared by both the octahedral sheet and the tetrahedral sheet, while the gallery or interlayer region is formed by Van der Waals forces that hold the layers together. Isomorphic substitution within the layers will generate negative charges, which will be counterbalanced by alkali and alkaline earth cations inside the galleries [27]. The thickness of the layers is of the order of $1 \mathrm{~nm}$. Thus, the clay layers are truly nanoparticulate. Based on information in the literature [27], the original layer silicates can only be dispersed in hydrophilic polymers, such as polyvinyl alcohol and polyethylene oxide. Thus, the normally or naturally hydrophilic layer silicates should be modified to become organophilic so that they can be more compatible with other polymer matrices. As a result, the exfoliation and intercalation of various polymers can be achieved.

Various modification methods are being used in the production of organically modified nanoclay. Early methods used amino acids [28]; however, primary, secondary, tertiary, or quaternary alkyl-ammonium cations were subsequently and widely used because they can be changed easily with the ions located between the layers. Alkyl-ammonium cations can provide sufficient functional groups that can react with the polymer matrix, thereby starting monomer polymerisation and enhancing the strength of the interface. The alkylammonium cations also expand the clay galleries (interlayer spacing) due to reduced surface energy, and consequently the polymer chains can penetrate the clay gallery space or be intercalated into the galleries [29].

There are three possible structures of polymer/layered silicate, and this depends on the types of the layered silicate, organic modifier, polymer matrix, and method of polymer nanocomposites preparation. The nanocomposite is said to be agglomerated when the polymer matrix is not able to expand and unable to cover the distances between the interlayer galleries and also unable to expel tactoids from the polymer to form microcomposites. The exfoliated or delaminated polymer nanocomposite is achieved when the individual silicate layers are uniformly dispersed in a continuous polymer matrix by an average distance. The intercalated structure is achieved when a single extended polymer chain is intercalated between the silicate layers, which results in a well-ordered multilayer [29].

A modified version of the montmorillonite nanoclay type is oMMT or organoclay. The modification of the montmorillonite nanoclay to an organoclay alters it, organically making the oMMT more organophilic and compatible with hydrophobic materials, such as silicone rubber, epoxy resin, and PE. Organoclays are reported to have charge carrier trapping properties (electronegative), provide an improved balance of stiffness and toughness, possess flame retardant properties that offer a reduction in relative heat release, and reduce dripping by forming char. They are also cheaper than other nanomaterials because they are produced in existing full-scale production facilities and because their basic materials come from readily available natural sources $[13,30]$.

\section{Experimental Technique}

3.1. Sample Preparation. The silicone rubber ( $\mathrm{SiR}$ ) used in this study was Sylgard 184 silicone elastomer which comes together with dimethyl, methylhydrogen siloxane as a hardener. Meanwhile, the oMMT used in this study was Nanomer 1.30P supplied by Nanocor Inc., USA. A detailed description on the materials, method used to prepare the organomontmorillonite by adding octadecylamine and concentrated hydrochloric acid, and also leaf-like sample preparation can be found in $[17,28]$ and [29], respectively.

3.2. Dispersion and Characterization Study. Dispersion of the nanoparticles inside the investigated materials was observed under a Carl Zeiss Supra 35 Field Emission Scanning Electron Microscope (FESEM), which is an ultrahigh-resolution microscope. Prior to FESEM observation, each fractured surface of nanocomposite sample was sputter-coated with a thin layer of platinum using a Bio-Rad sputter coater under vacuum pressure for one minute at $20 \mathrm{~mA}$ and $1.6 \mathrm{kV}$ to provide electrical conductivity. The nanocomposite samples were then examined at $10 \mathrm{kV}$ of acceleration voltage. In addition, the dispersion of nanofiller inside the silicone rubber material was also observed by $200 \mathrm{kV}$ high-resolution transmission electron microscope (HRTEM). The sample was sliced into excellent quality ultrathin $200 \mathrm{~nm}$ thick slices by using a Leica EM FC7 cryoultramicrotome.

A Fourier transform infrared spectrometer (FTIR) was used to identify the functional groups on the surface and in the bulk of the used filler and in the polymer-based nanocomposite samples. These functional groups help to 


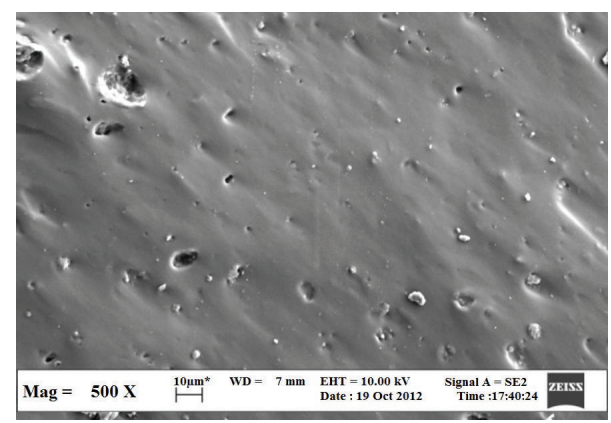

(a)

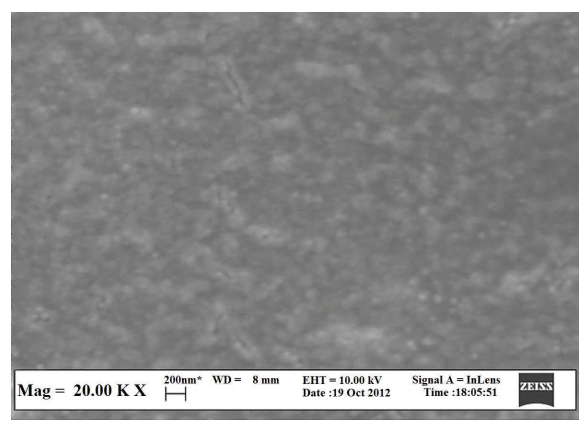

(b)

FIGURE 1: FESEM images of fractured surfaces for silicone rubber-based nanocomposites: (a) $1 \mathrm{wt} \%$ and (b) $3 \mathrm{wt} \%$.

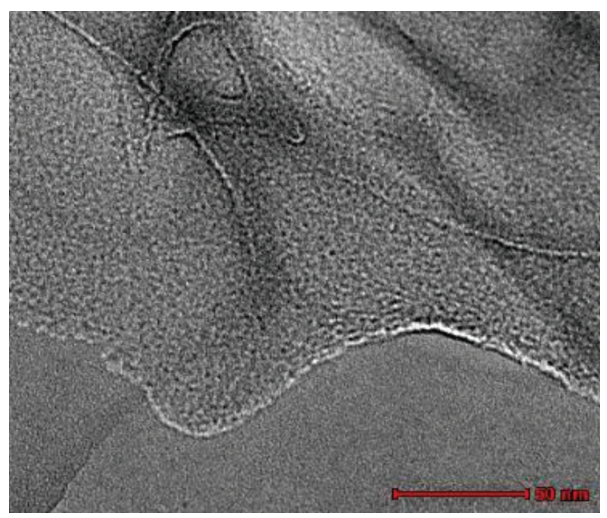

(a)

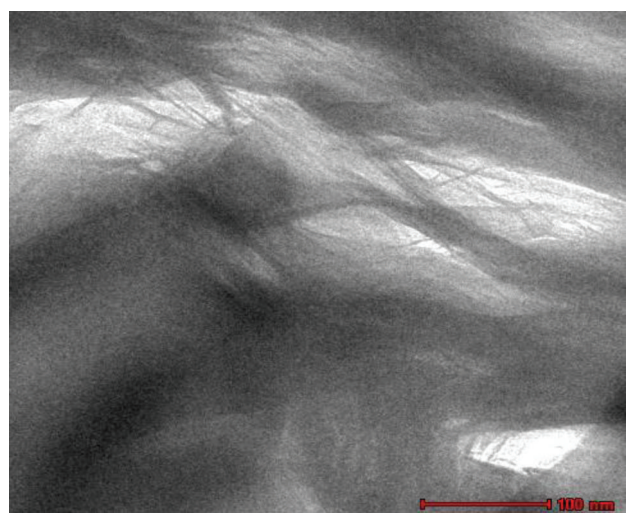

(b)

FIgURE 2: TEM micrographs of silicone rubber-based nanocomposites: (a) $1 \mathrm{wt} \%$ and (b) $3 \mathrm{wt} \%$.

clarify the interaction between the nanofiller and the polymer (silicone rubber) at the interface of the nanocomposites. A Perkin Elmer FTIR spectrometer was used to obtain the IR spectra. The polymer specimens were analysed at $1 \mathrm{~cm}^{-1}$ resolution, and 16 scans were averaged in the transmittance mode at wavelengths in the range of $370-4000 \mathrm{~cm}^{-1}$. The nanofillers were pressed with potassium bromide $(\mathrm{KBr})$ at a pressure of 6 bars to form a thin film disc for FTIR measurements. The thin film disc was then placed in a sample cap of diffuse reflectance fitment. Before the FTIR preparation, the oMMT nanofiller and the sample of silicone rubber-based nanocomposites were dried at $105^{\circ} \mathrm{C}$ for more than 48 hours to ensure removal of all moisture for the FTIR analysis. The spectra were analysed via the software provided with the instrument.

3.3. Experimental Procedure. The electrical treeing-PD test rig consists of a step-up transformer, fibre optic transmitter and receiver, high voltage supply, Peltier cooled Charged Couple Device (CCD) camera with back illumination, light emitting diode (LED), digital storage oscilloscope, temperature controller with cartridge heater, specimen holder, glass test cell, RLC load circuit, and personal computer. A detailed description of the test rig and experimental procedure using the test rig can be found in [29-31].

\section{Results and Discussion}

4.1. Nanofiller Dispersion via FESEM. The FESEM and TEM images are depicted in Figures 1 and 2, respectively. These visual analyses were able to characterize and clarify the dispersion, degree, and homogeneity of agglomeration of the nanoparticles into the nanocompounds. Under a magnification of 500 times, several tactoids were visible and can be seen in Figure 1(a) where the agglomerated nanoparticle sizes are larger than $100 \mathrm{~nm}$; the nanoparticle sizes in Figure 1(b) are smaller and less than $100 \mathrm{~nm}$.

4.2. Electrical Treeing, PD, and Effect of Temperature. All the electrical trees were noted to have grown below an estimated electrical tree inception voltage of $10 \mathrm{kVrms}$ at $50 \mathrm{~Hz}$. Images of the light emitted from PD within the tree channels that were recorded before voltage was removed at the end of each experiment are shown in Figures 3 and 4. These composite images of light emission are due to the partial discharge activity (grey scale) superimposed on the back-illuminated images (red/black) of the tree structure. These images show the spatial extent of the PDs within the tree channel that formed. All trees formed were found to have a branched structure.

In the case of neat resin samples ( $0 \mathrm{wt} \%$ oMMT), the tree inception time was found to have decreased with increase in 

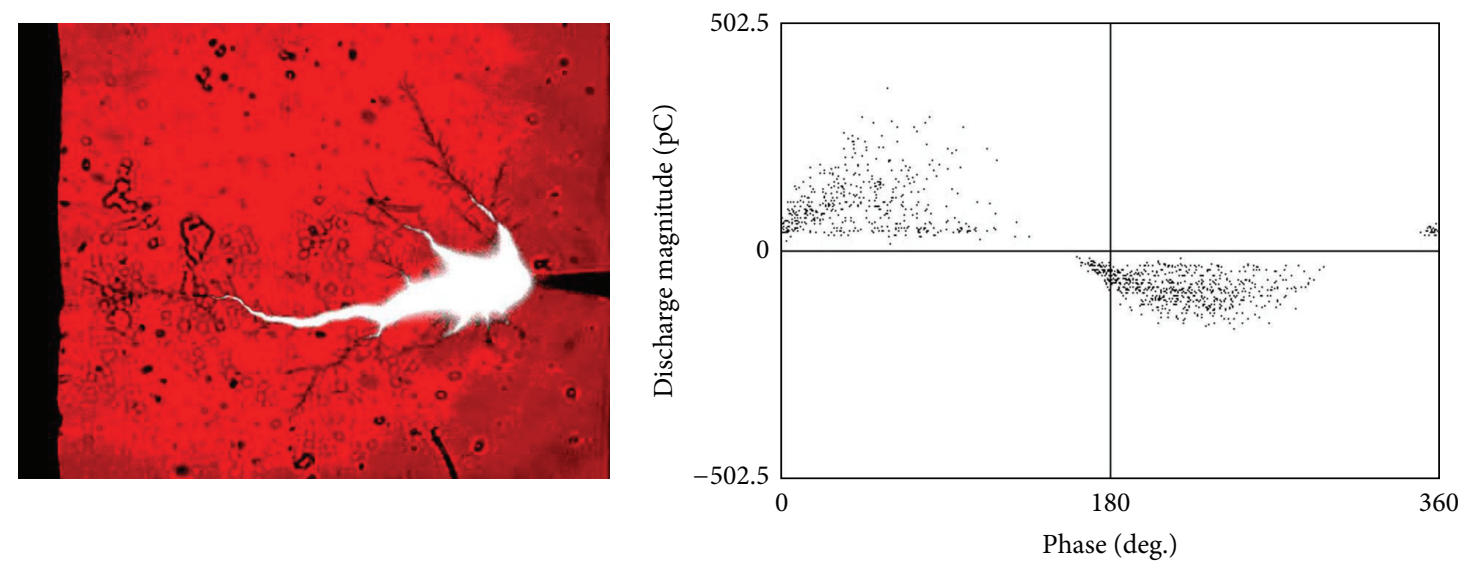

(a)
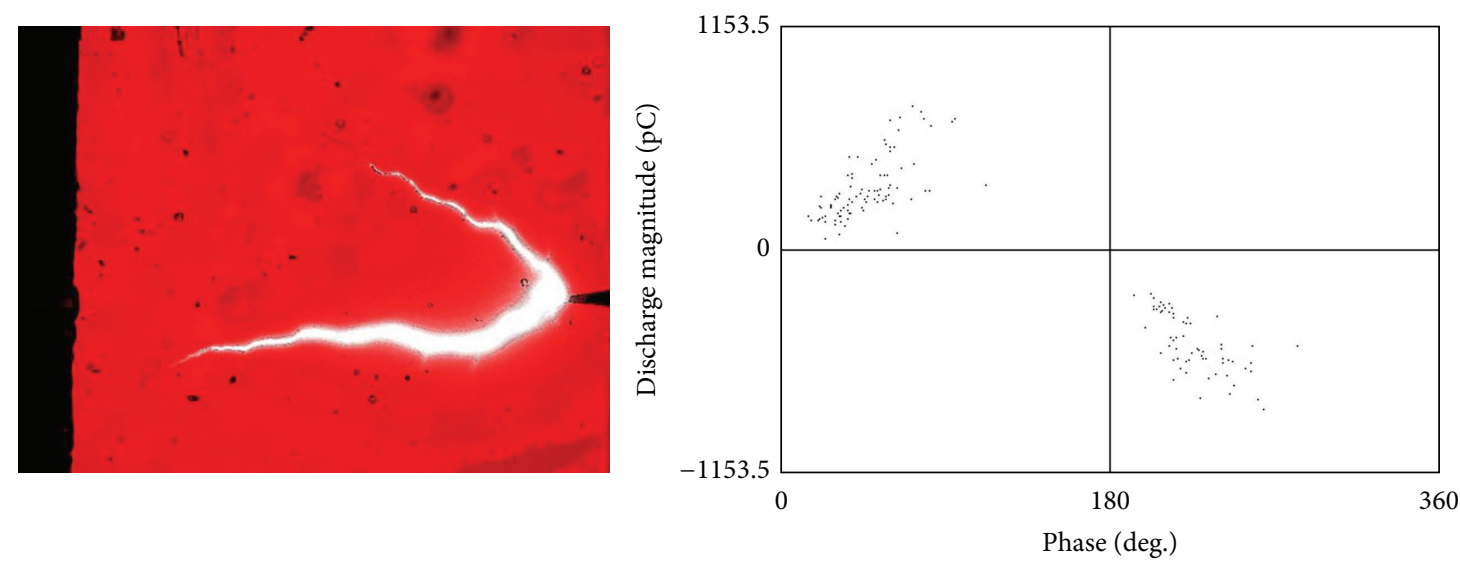

(b)
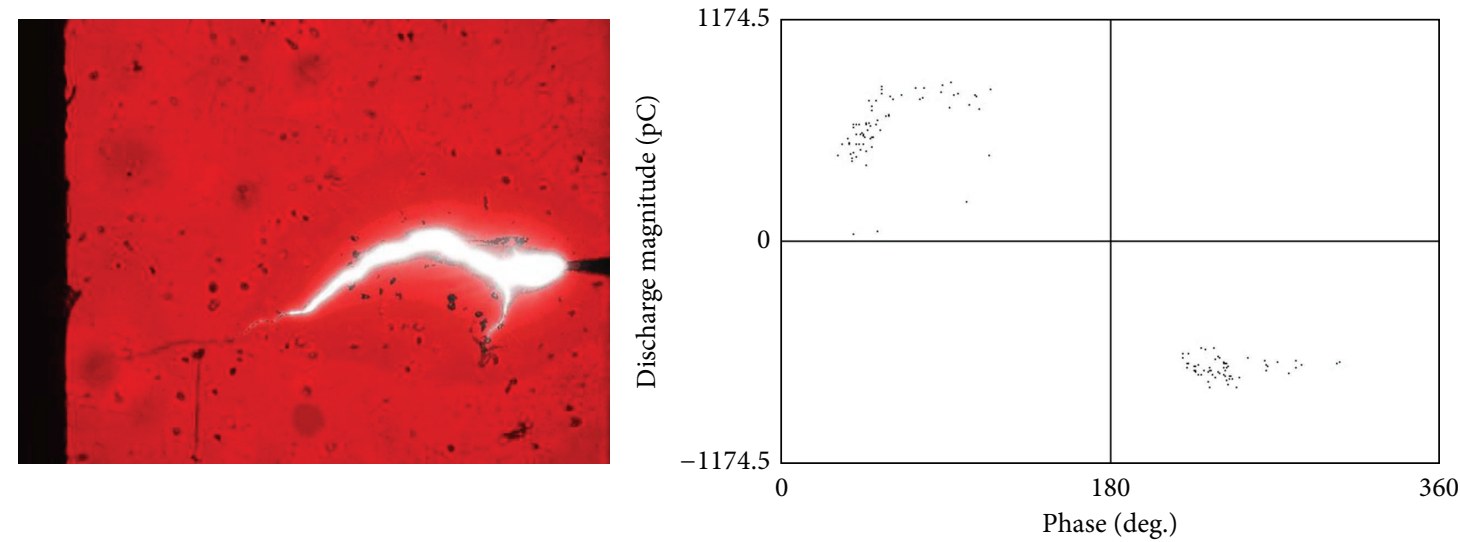

(c)

FIGURE 3: Electrical treeing associated with the PD phase-resolved patterns of neat silicone rubber: (a) at $20^{\circ} \mathrm{C}$, (b) at $40^{\circ} \mathrm{C}$, and (c) at $60^{\circ} \mathrm{C}$.

temperature from 19 seconds at $20^{\circ} \mathrm{C}$ to 5 seconds at $60^{\circ} \mathrm{C}$. In contrast, the tree growth time required for the tree to grow approximately $95 \%$ of the pin-edge distance increased from 80 seconds at $20^{\circ} \mathrm{C}$ to approximately 29 minutes at $60^{\circ} \mathrm{C}$. The tree initiation process starts from injection and extraction of space charges in which the charge carrier dynamics depend significantly on temperature as these processes are mostly thermally activated mechanisms [32]. Thus, the increase in temperature enhances the dynamics of the space charge, reducing the tree initiation time. In addition, the increase in temperature gives rise to an increase in the number of cross-link network structures caused by the vulcanization process. This results in more trapping sites for charge carriers where the charge carriers get trapped around the boundary of the polymer chains, reducing the charge carrier mobility. This slows down the growth of the electrical tree due to 

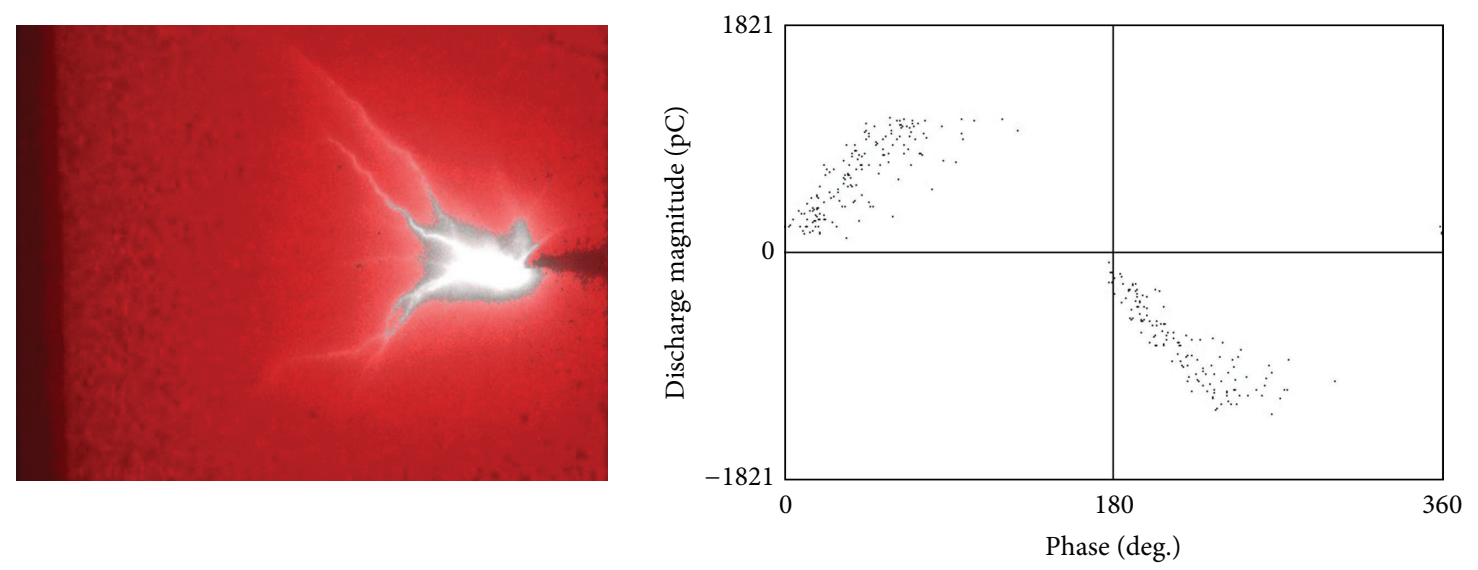

(a)
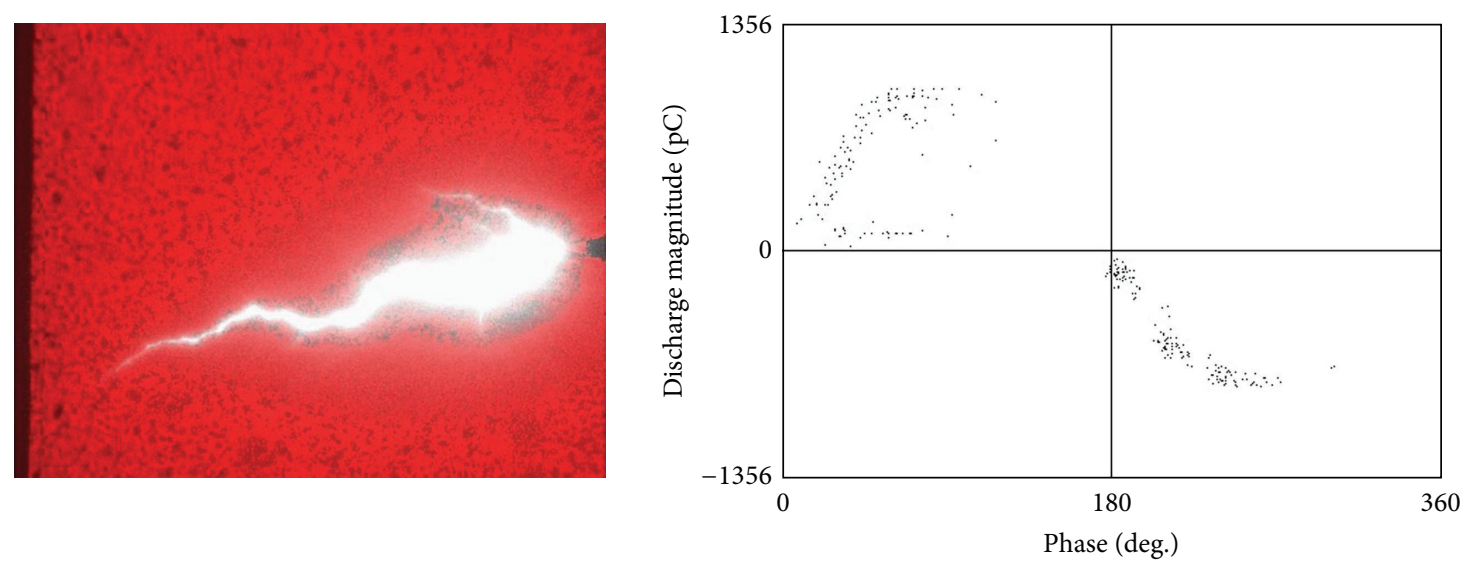

(b)
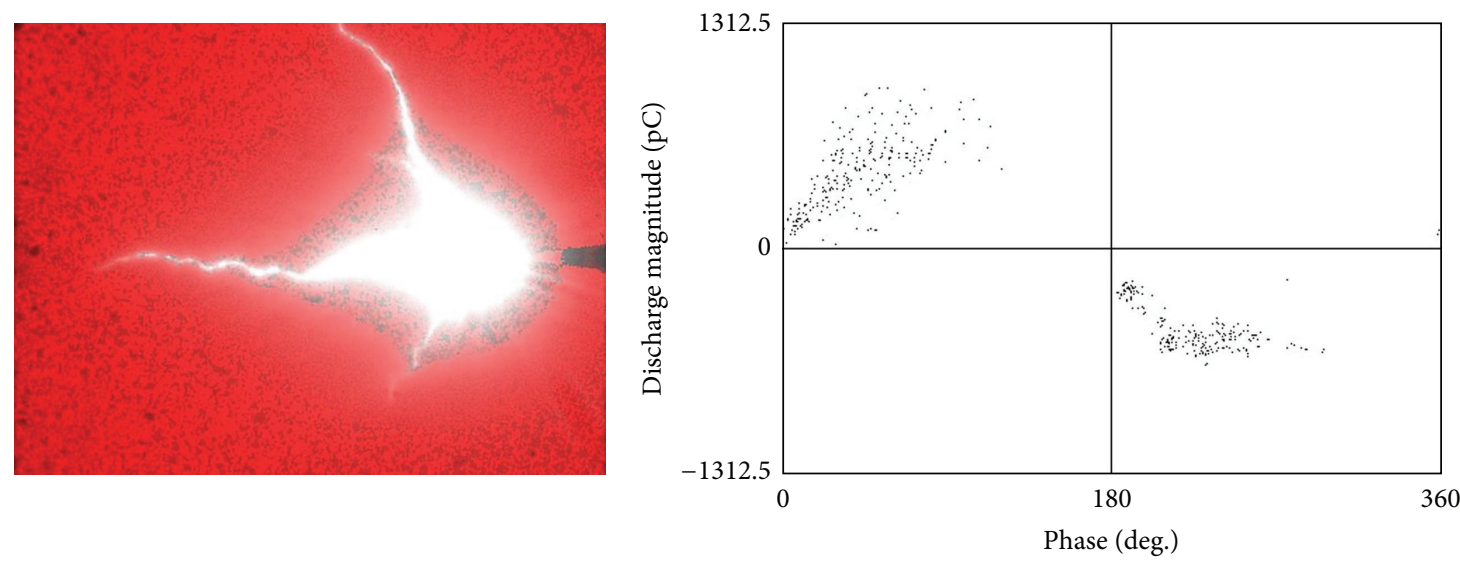

(c)

FIGURE 4: Electrical treeing associated with the PD phase-resolved patterns of silicone rubber-based nanocomposite ( $1 \mathrm{wt} \%)$ : (a) at $20^{\circ} \mathrm{C}$, (b) at $40^{\circ} \mathrm{C}$, and (c) at $60^{\circ} \mathrm{C}$.

more time and energy required to detrap the charge carriers for conduction. In addition, the increase in the number of cross-link networks also creates a more rigid polymer with an immobilized polymer chain. Consequently, more energy and time are required to break the bond to create a void or cavity, which eventually generates PD and causes the growth of electrical treeing.
In the case of the $1 \mathrm{wt} \%$ oMMT nanocomposites, the inception time first increased and then decreased with increasing temperature. The registered tree inception times were 20 seconds, 100 seconds, and 83 seconds at $20^{\circ} \mathrm{C}$, $40^{\circ} \mathrm{C}$, and $60^{\circ} \mathrm{C}$, respectively. Nevertheless, the addition of nanofiller enhanced the tree initiation time even though the temperatures increased. As mentioned before, the space 
charge dynamics were enhanced by increasing the temperature. However, the effect of temperature on space charges in silicone rubber-based nanocomposites was not obvious since the addition of nanoparticles trapped the charge carriers around or inside the particles. Thus, these trapped charge carriers require high energy to move from one trap to another trap or to get extracted from the polymer. This results in a slower degradation rate and more time for tree initiation.

The tree growth times were significantly higher for the $1 \mathrm{wt} \%$ oMMT nanocomposite samples than for the neat silicone rubber samples. The tree growth times were found to increase from 10 minutes at $20^{\circ} \mathrm{C}$ to 46 minutes at $60^{\circ} \mathrm{C}$ due to the promotion of more cross-link networks as trapping sites. Moreover, the trapping sites were also enhanced due to the inclusion of nanoparticles. Thus, the injected and accumulated space charges were unable to drift or detrap since most of the space charges were trapped at the polymer chains and around or inside the nanoparticle. This resulted in more energy and time being needed for space charges to cause electrical tree propagation, thus prolonging the electrical growth time.

The initiation of a tree is a sign of initial conduction in the dielectric. Since conductivity is proportional to the elementary charge, carrier density, and carrier mobility [33], reduction of conductivity is presumably due to the capture of mobile carriers at polymer/filler interfaces. In silicone rubber-based nanocomposites material (3wt\%), the large total interfacial areas contribute to increasing the trapping probability of charge carriers. The increase of charge trap areas/sites leads to a reduction in charge mobility, which in turn reduces conduction. The trapping probability was also enhanced due to the vulcanization process, which made the nanocomposites more rigid; consequently, more energy and time were required for polymer decomposition. However, due to insufficient field energy, the trapped charge carriers (electrons and holes) combine at the recombination centre and emit the photon that is responsible for light emission. Therefore, in the case of the $3 \mathrm{wt} \%$ oMMT nanocomposites, no tree inception was observed; even after 4 hours of voltage application, only weak light emission and sporadic PDs were recorded.

By comparing the effect of the nanofiller at individual temperatures, we can note and justify the advantages or benefits and reinforcement properties of adding the nanofiller. At a low temperature of $20^{\circ} \mathrm{C}$, the tree inception time of silicone rubber nanocomposite $(1 \mathrm{wt} \%)$ was almost similar to the corresponding neat silicone rubber. This insensitive characteristic was due to the agglomeration in the nanocomposite sample (1 wt\%) as seen in the FESEM image in Figure 1(a). In addition, the TEM micrograph in Figure 2(a) shows that the clay silicate layers do not maintain their original parallel layers with a scattered layered structure. Thus, agglomeration nullifies the capability of electrical tree initiation resistance of nanoparticles, resulting in insensitive parameters. However, the increase in filler loading increased the growth time of electrical treeing due to the trapping of charge carriers.

When the temperature was increased to $40^{\circ} \mathrm{C}$, tree inception time and tree growth time increased with increases in filler loading from $0 \mathrm{wt} \%$ to $3 \mathrm{wt} \%$. These enhancements in electrical tree resistance result from the increase in the charge carrier trapping density and also from the increase in crosslink network structures. These changes result in difficulty in initiating an electrical tree since more field energy is needed to enhance growth.

More enhanced and reinforced properties of silicone rubber-based nanocomposites are noticed at a temperature of $60^{\circ} \mathrm{C}$. This postcure temperature promoted more cross-link network structures, thereby contributing to the formation of a more rigid polymer. This enhancement leads to an increase in electrical tree inception time and electrical tree growth time since nanofillers act as trapping sites and potential physical barriers to the growth of an electrical tree in the direction of the electric field.

The composite CCD images shown in Figures 3, 4, and 5 demonstrate that, for all samples in which trees grew, the PDs occur throughout the main body of the tree structure. This indicates that the tree channels were effectively electrically nonconducting, such that a sufficient potential difference could exist along the tree channels to initiate PDs within them. In addition to the composite images captured, the phase-resolved PD patterns were also recorded. Generally, the PD pulses mainly occurred in the first and third quadrants of the voltage waveform.

The results of the phase-resolved PD data are shown in Table 1 . In the case of neat $\mathrm{SiR}$, the average PD magnitude was found to increase with increase in temperature while the average number of PDs per second was found to decrease with increase in temperature. A significant shift in the average phase of PD occurrence of both the positive and negative discharge distributions took place simultaneously. The average phase of occurrence of the positive PDs increased from $37^{\circ}$ at $20^{\circ} \mathrm{C}$ to $55^{\circ}$ at $60^{\circ} \mathrm{C}$. Similar dependence on temperature of the $\mathrm{PD}$ phases was found for electrical tree growth in the flexible epoxy resin. This phase shift is attributed to an increase in the electrical conductivity of the epoxy resin with increasing temperature, leading to decreased accumulation of the space charge surrounding the tree structure.

However, the reverse situation has been reported for an epoxy resin sample; that study showed PD numbers increasing and $\mathrm{PD}$ magnitudes decreasing with increasing temperature from $20^{\circ} \mathrm{C}$ to $70^{\circ} \mathrm{C}$ [34]. This dissimilarity between epoxy resin and silicone rubber is probably due to the increase in vulcanization/cross-link numbers in silicone rubber matrices with increasing temperature; this has been discussed thoroughly by Du et al. $[15,35]$.

In the case of the $1 \mathrm{wt} \%$ oMMT nanocomposite, the average $\mathrm{PD}$ magnitude was found to decrease with increasing temperature from $450 \mathrm{pC}$ at $20^{\circ} \mathrm{C}$ to $257 \mathrm{pC}$ at $60^{\circ} \mathrm{C}$. However, the other three $\mathrm{PD}$ physical parameters remained relatively insensitive to the changes in temperature. The decrease in PD magnitude when the temperature increased in silicone rubber-based nanocomposites ( $1 \mathrm{wt} \%)$ is because the addition of nanoparticles contributes to the trapping of space charges; in this process, the electrons injected from the electrode move towards the opposite electrode and are trapped at the nanoparticle surfaces and inside the nanoparticles. When the applied field is sufficiently high, it can cause ionization of the nanoparticle within the polymer. Thus, an internal field will 
TABLE 1: Summary of partial discharge statistical parameters.

\begin{tabular}{|c|c|c|c|c|c|c|c|c|c|c|}
\hline \multirow{2}{*}{ Type of sample } & \multirow{2}{*}{ PD characteristics } & \multicolumn{3}{|c|}{$20^{\circ} \mathrm{C}$} & \multicolumn{3}{|c|}{$40^{\circ} \mathrm{C}$} & \multicolumn{3}{|c|}{$60^{\circ} \mathrm{C}$} \\
\hline & & Min & Max & Ave. & Min & Max & Ave. & Min & Max & Ave. \\
\hline \multirow{5}{*}{ Neat SiR } & Discharge magnitude (pC) & 83 & 218 & 160 & 57 & 387 & 280 & 70 & 610 & 332 \\
\hline & Number of PDs $\left(\mathrm{s}^{-1}\right)$ & 687 & 1244 & 952 & 117 & 7571 & 199 & 65 & 649 & 197 \\
\hline & Phase of occurrence of positive PDs $\left(^{\circ}\right)$ & 34 & 41 & 37 & 36 & 60 & 44 & 44 & 93 & 55 \\
\hline & Phase of occurrence of negative PDs $\left(^{\circ}\right)$ & 215 & 220 & 218 & 218 & 244 & 226 & 223 & 247 & 239 \\
\hline & Dissipated power $(\mathrm{mW})$ & 0.87 & 1.40 & 1.24 & 0.35 & 3.4 & 0.54 & 0.05 & 0.997 & 0.668 \\
\hline \multirow{5}{*}{$\mathrm{SiR} / 1$ wt $\%$ oMMT } & Discharge magnitude (pC) & 31 & 641 & 450 & 5 & 492 & 294 & 137 & 478 & 257 \\
\hline & Number of PDs $\left(\mathrm{s}^{-1}\right)$ & 249 & 1831 & 495 & 1 & 581 & 338 & 416 & 831 & 580 \\
\hline & Phase of occurrence of positive PDs $\left(^{\circ}\right)$ & 33 & 86 & 44 & 36 & 61 & 47 & 34 & 44 & 38 \\
\hline & Phase of occurrence of negative PDs $\left(^{\circ}\right)$ & 209 & 275 & 223 & 209 & 274 & 217 & 212 & 225 & 217 \\
\hline & Dissipated power $(\mathrm{mW})$ & 0.22 & 3.50 & 1.91 & 0.061 & 1.5 & 0.94 & 0.75 & 2.00 & 1.395 \\
\hline \multirow{5}{*}{$\mathrm{SiR} / 3$ wt $\%$ oMMT } & Discharge magnitude (pC) & 2 & 45 & 22 & 2 & 6 & 4 & 2 & 11 & 4 \\
\hline & Number of PDs $\left(\mathrm{s}^{-1}\right)$ & 1 & 643 & 181 & 1 & 64 & 27 & 1 & 25 & 4 \\
\hline & Phase of occurrence of positive PDs $\left(^{\circ}\right)$ & 17 & 142 & 80 & 5 & 94 & 46 & 52 & 133 & 75 \\
\hline & Phase of occurrence of negative PDs $\left({ }^{\circ}\right)$ & 154 & 306 & 280 & 177 & 272 & 226 & 164 & 265 & 222 \\
\hline & Dissipated power $(\mu \mathrm{W})$ & 0.34 & 163 & 35.7 & 0.002 & 3.7 & 1.13 & 0.03 & 0.98 & 0.15 \\
\hline
\end{tabular}

be created to oppose the direction of the applied field, making the net field inside the nanoparticle greater than the discharge inception field and thereby extinguishing the discharge. This reduces the PD magnitude. If the applied field is high enough and exceeds the internal field, the discharge will occur again. However, the particles tend to agglomerate, resulting in the less interfacial area and leading to lesser charge carriers getting trapped around the particle surfaces (localized states). Due to repetition and a sufficiently high electric field, the trap sites provided by microparticles for electron localizations are not sufficient and so lead to electron drift (detrapping). This causes charge movements (mobility) that give a higher PD repetition rate. As a result, agglomeration nullifies the capability of PD resistance of the nanoparticles.

The addition of $3 \mathrm{wt} \%$ oMMT nanoparticles in silicone rubber caused electrical tree inhibition; no electrical trees were observed during the time span of the experiment (4 hours at $10 \mathrm{kVrms}, 50 \mathrm{~Hz}$ ). Only localized light emission, recognized as electroluminescence, was detected at the needle tip when using the CCD camera. It appears that the SiR matrices were reinforced by the addition of $3 \mathrm{wt} \%$ oMMT nanofillers to an extent that prevented the formation of an initial void with a sufficient dimension required for PD generation and subsequent electrical tree initiation. The PD magnitudes and PD numbers decreased with the increase in temperature from $20^{\circ} \mathrm{C}$ to $60^{\circ} \mathrm{C}$; the $\mathrm{PD}$ magnitudes decreased from $22 \mathrm{pC}$ to $4 \mathrm{pC}$. However, the phase of positive PDs was found to be insensitive to temperature changes, whereas the phase of negative PDs shifted to the lower values with the increase in temperature.

Based on FESEM images in Figure 1(b), the nanofillers were distributed uniformly with sizes less than $100 \mathrm{~nm}$. The micrograph in Figure 2(b) shows that the oMMT was in the form of incompletely exfoliated mixed intercalation, indicating that the silicate layers were uniformly separated as the particles were quite long in length. The TEM image in Figure 2(b) shows that the nanocomposite material containing oMMT particles differed from the form shown in the FESEM image of Figure 1(b). However, the oMMT particles still maintained the parallel layered structures even though the gap increased.

Thus, oMMT possesses the advantages of nanoparticles, such as a large interfacial area (surface area) that allows large charge carrier trapping, charge dissipation due to recombination, electron scattering, large interaction zones, and a proximity effect [36]. These properties reduce the charge mobility and energy needed for conduction, thereby reducing PD magnitudes, PD numbers, and other PD parameters. The charge carriers are unable to move (drift) due to insufficient kinetic energy and remain at the electrode tip; most are dissipated by electron-hole recombination, which releases energy (photon) in the form of light.

Moreover, the small discharges detected in the nanocomposites material were probably swarming partial microdischarges (SPMD); this is related to the existence of microvoids at the polymer/electrode interface due to imperfect bonding between the tungsten needle and the silicone rubber. Tanaka [37] reported that small PDs of less than $1 \mathrm{pC}$ were detected in a void prior to tree initiation. SPMD phenomena can be found in [38-40]. Thus, the detection of PD prior to tree initiation may have been caused by the microvoids at the needle tip due to charge carrier recombination. The holes and electrons were injected into the polymer during the positive and negative half-cycle of the AC voltage and were trapped in the recombination centres. Light is emitted when the electron-hole recombination occurs at the luminescent centre [41]. However, the electric field intensity was insufficient to initiate electrical treeing due to low energy.

In polymer nanocomposites, the nanoparticles act as charge carrier trap with high barrier potentials. These trapped carriers need more energy to get extracted from one trap to another trap. This would slow down the growth of electrical 

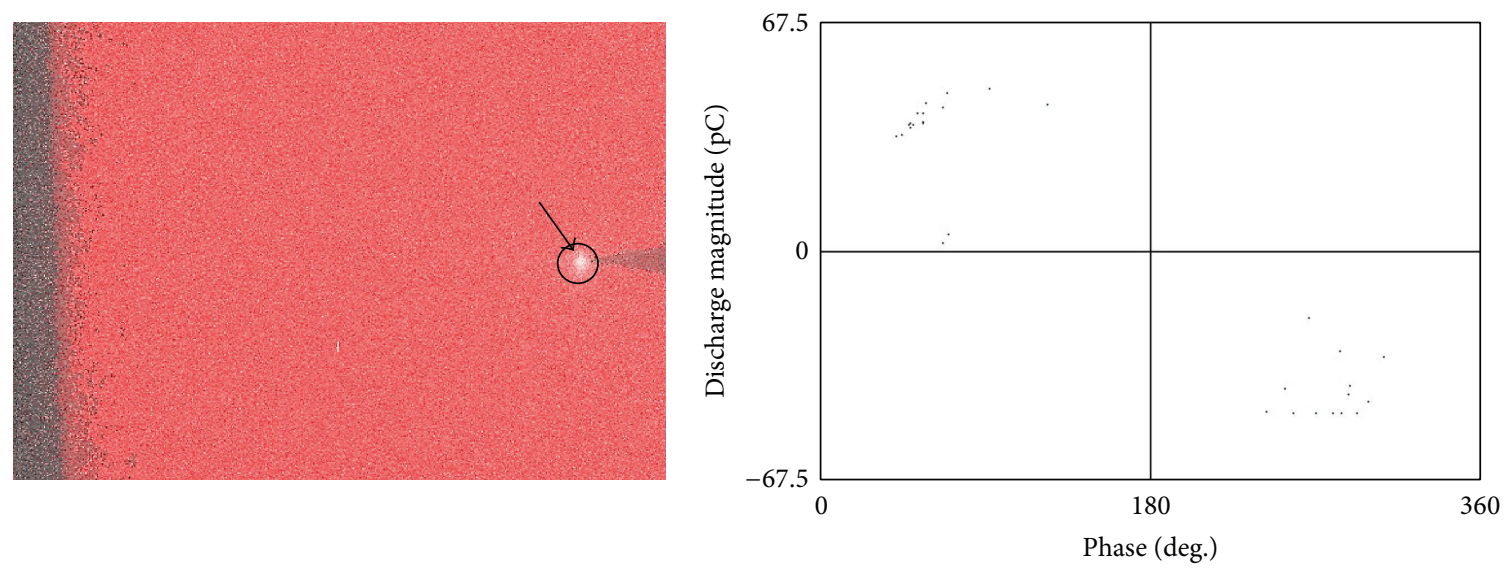

(a)
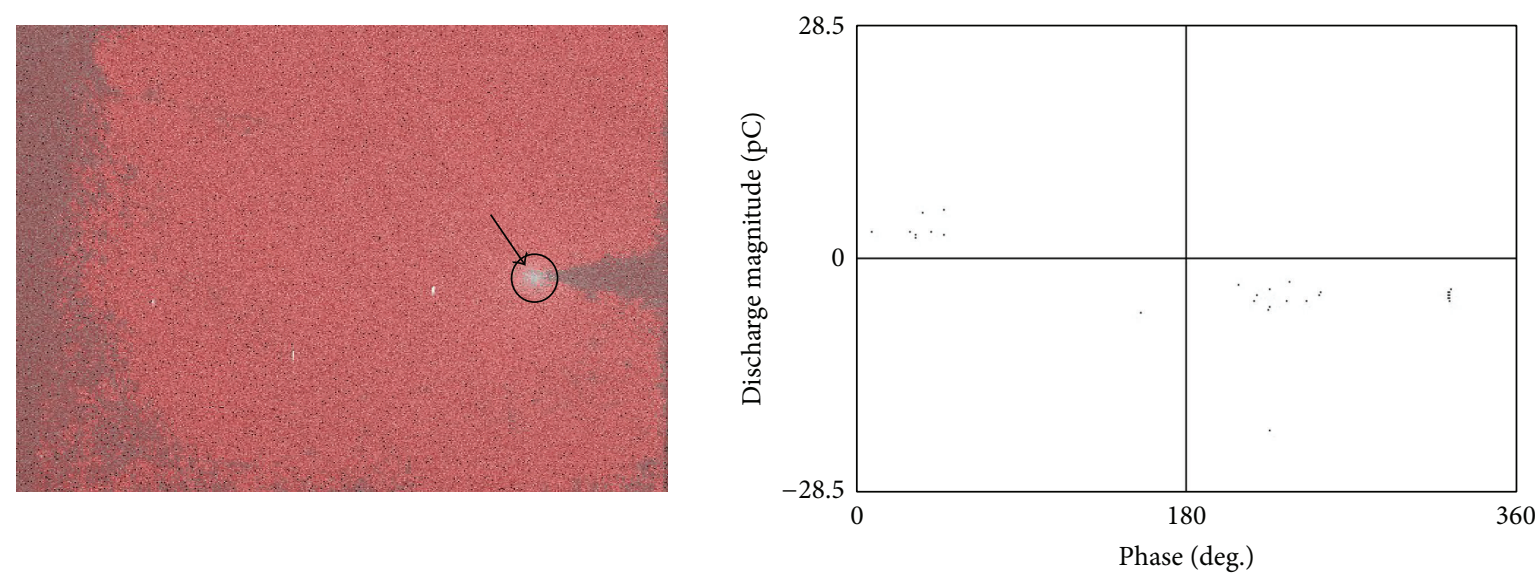

(b)
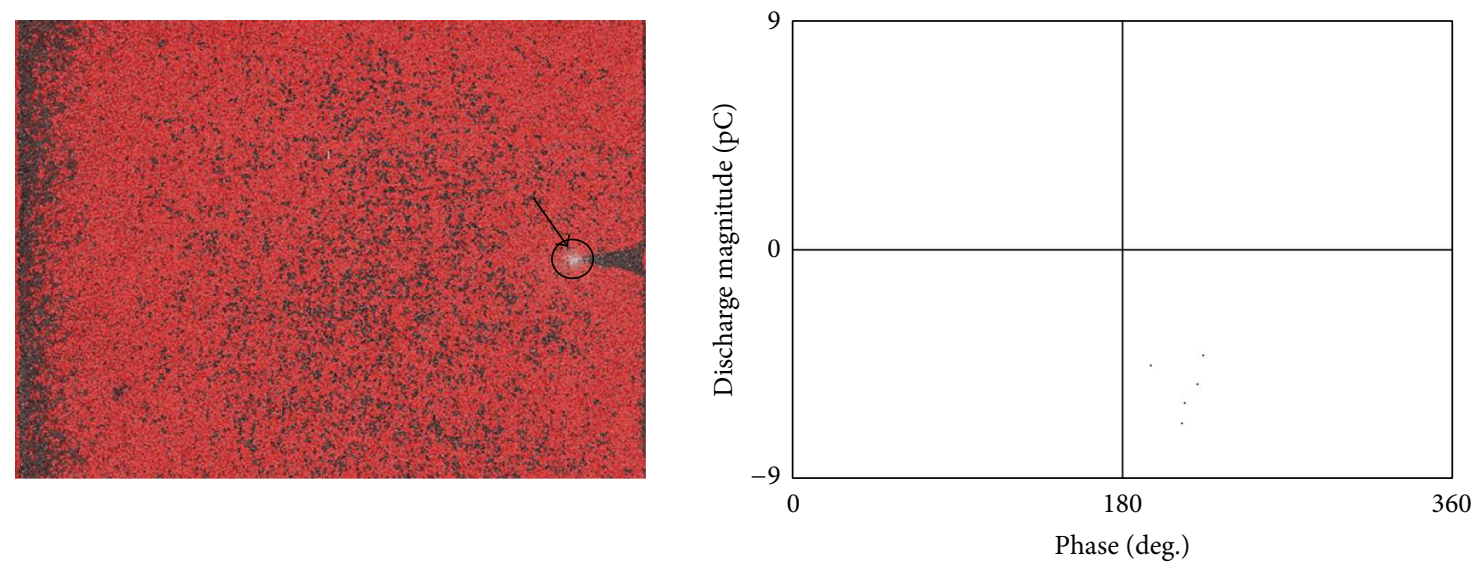

(c)

FIGURE 5: Electrical treeing associated with the PD phase-resolved patterns of silicone rubber-based nanocomposite $(3 \mathrm{wt} \%):(\mathrm{a})$ at $20^{\circ} \mathrm{C},(\mathrm{b})$ at $40^{\circ} \mathrm{C}$, and (c) at $60^{\circ} \mathrm{C}$; arrows indicate weak light emissions.

treeing [42]. With the addition of $1 \mathrm{wt} \%$ oMMT nanofillers, tree inception time and propagation time were distinctly enhanced. However, PD magnitudes and PD numbers of silicone rubber-based nanocomposite (1 wt\%) became insensitive with the increase in temperature as evidenced by the PD magnitudes being higher than neat silicone rubber at $20^{\circ} \mathrm{C}$ and $40^{\circ} \mathrm{C}$ whereas the PD numbers of silicone rubber-based nanocomposite ( $1 \mathrm{wt} \%$ ) were greater than neat silicone rubber at $40^{\circ} \mathrm{C}$ and $60^{\circ} \mathrm{C}$. We attribute the reason for the increase in PD magnitudes and PD numbers to agglomeration of the nanofiller in the silicone rubber matrix. The tactoids represent the weak points that could enhance PD repetition inside 


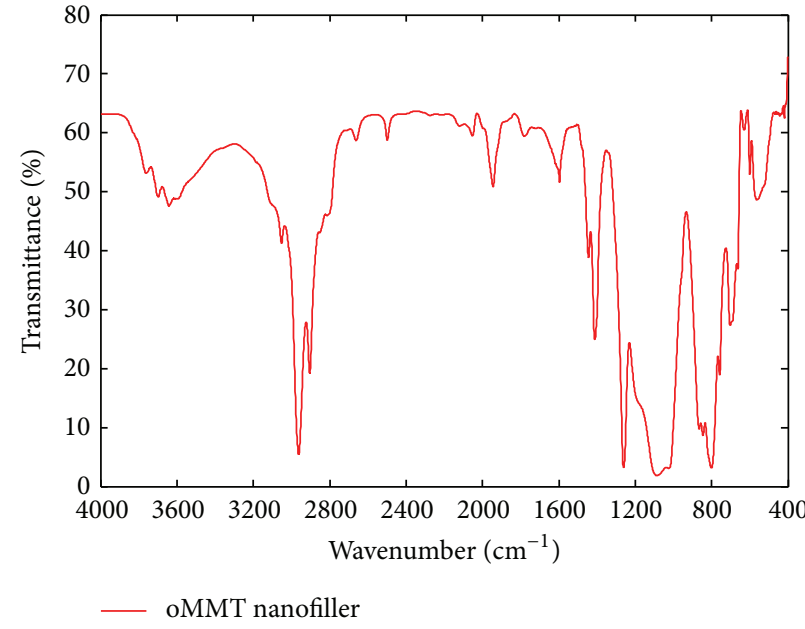

(a)

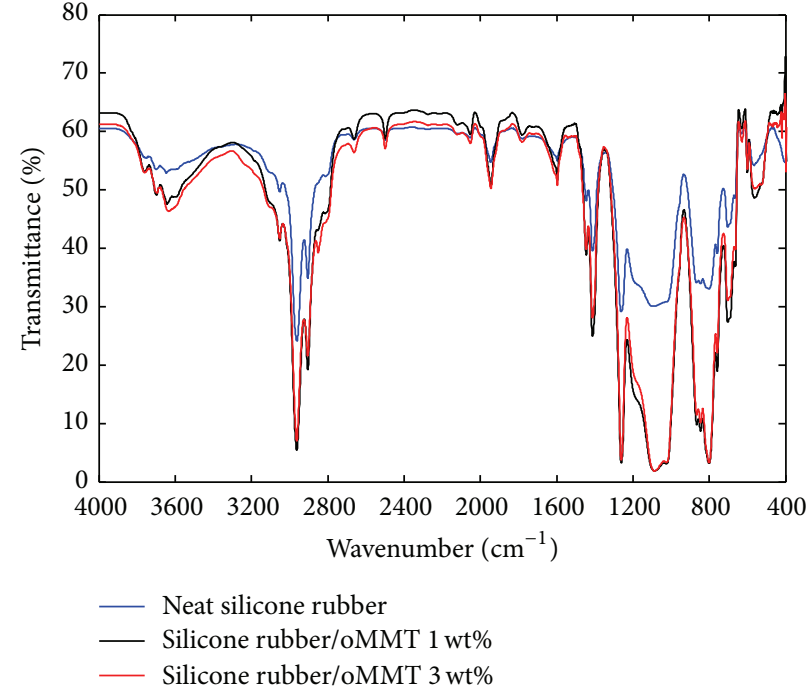

(b)

FIGURE 6: FTIR spectra. (a) oMMT nanofiller is denoted by the red line. (b) Neat silicone rubber is denoted by the blue line, silicone rubberbased nanocomposite ( $1 \mathrm{wt} \%)$ is denoted by the black line, and silicone rubber-based nanocomposite (3 wt $\%)$ is denoted by the red line.<smiles>CC[Si](C)(C)O[Si](C)(C)O[Si](C)(C)O[Si](C)(C)C</smiles>

Figure 7: Chemical structure of polydimethylsiloxane of silicone rubber [26].

the polymer. This is depicted in Figure 1(a), which shows agglomeration of filler particles sizes greater than $100 \mathrm{~nm}$ occurring inside the silicone rubber-based nanocomposite sample with $1 \mathrm{wt} \%$ oMMT nanofiller. However, agglomerated nanoparticles larger than $100 \mathrm{~nm}$ are considered to be microparticles. Microparticles have also contributed to the suppression of an electrical tree $[43,44]$ by acting as a physical barrier to the growth of tree channels, resulting in the tree forming more side branches when it collided with the microparticles.

\section{Chemical Bonding Study via FTIR}

FTIR spectra could be used to show the nature of bonding or chemical changes of neat silicone rubber and silicone rubberbased nanocomposite structures. FTIR spectra of oMMT filler and silicone rubber-based nanocomposites (1 wt $\%$ and 3 wt\%) are depicted in Figure 6. The chemical structure (ring molecule) of silicone rubber is depicted in Figure 7 [26].

Silicone rubber consists of organic methyl groups $\left(\mathrm{CH}_{3}\right)$ and a silicone-oxygen backbone. The methyl groups are responsible for water repellence, surface hardness, and noncombustibility, whereas the vinyl groups $\left(\mathrm{CH}=\mathrm{CH}_{2}\right)$ help
TABLE 2: Neat silicone rubber IR band characteristics (polydimethylsiloxane) [48].

\begin{tabular}{lc}
\hline Wavenumber $\left(\mathrm{cm}^{-1}\right)$ & Bond \\
\hline $3700-3200$ & $\mathrm{OH}$ \\
$2960-2762$ & $\mathrm{CH}$ in $\mathrm{CH}_{3}$ \\
1640 & $\mathrm{OH}$ in $\mathrm{H}_{2} \mathrm{O}$ \\
$1440-1410$ & $\mathrm{CH}$ \\
$1270-1255$ & $\mathrm{Si}-\mathrm{CH}_{3}$ \\
$1200-1000$ & $\mathrm{Si}-\mathrm{O}-\mathrm{Si}$ \\
$870-850$ & $\mathrm{Si}\left(\mathrm{CH}_{3}\right)_{3}$ \\
$840-790$ & $\mathrm{Si}\left(\mathrm{CH}_{3}\right)_{2}$ \\
700 & $\mathrm{Si}\left(\mathrm{CH}_{3}\right)$ \\
\hline
\end{tabular}

to strengthen the rigidity of the molecular structure by creating easier cross-linkage of the molecules $[45,46]$. The silicone rubber was vulcanized to give the required solid shape. Vulcanization and cross-linking are terms that refer to the formation of chemical bonds between polymeric chains attained under high pressure and high temperature [26]. The increase in the number of hydrocarbon vinyl groups $\left(-\mathrm{CH}_{2}\right)$ is associated with the increase in the number of cross-links as this group is part of the silicone cross-link domain [47, 48]. Moreover, the presence of cross-links reduces the swelling (bending) capacity and inhibits the transfer of polymer chains into solution [49]. Possible bonds in the neat silicone rubber (polydimethylsiloxane, PDMS) are presented in Table 2.

Based on the FTIR spectra of the oMMT nanofiller in Figure 6(a), peaks occur at $3631 \mathrm{~cm}^{-1}, 3427 \mathrm{~cm}^{-1}, 3246 \mathrm{~cm}^{-1}$, $2920 \mathrm{~cm}^{-1}$, and $2850 \mathrm{~cm}^{-1}$. The peak at $3631 \mathrm{~cm}^{-1}$ corresponds to broadening of the stretching vibration of hydroxyl groups $(-\mathrm{OH})$, whereas the peaks at $3427 \mathrm{~cm}^{-1}$ and $3246 \mathrm{~cm}^{-1}$ indicate the stretching vibration of the amine 


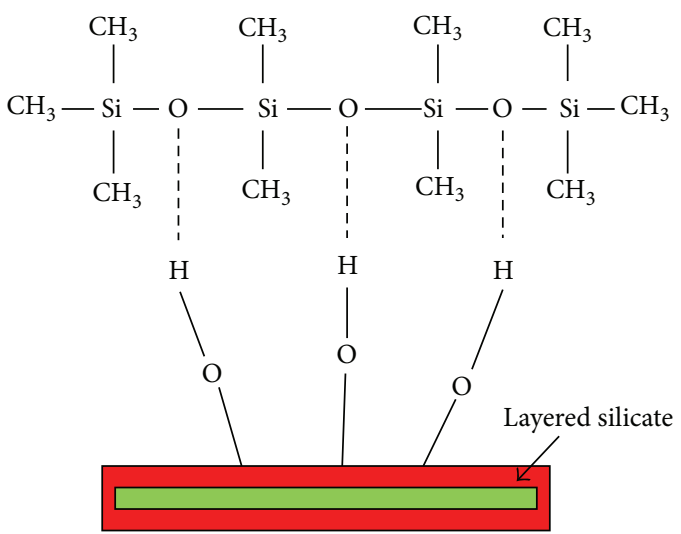

Figure 8: Possible interface model between nanoparticle and silicone rubber segments.

group $(\mathrm{N}-\mathrm{H})$ due to modification with octadecylamine. The peaks at $2920 \mathrm{~cm}^{-1}$ and $2850 \mathrm{~cm}^{-1}$ correspond to $-\mathrm{CH}$ stretching vibrations of the methyl group $\left(-\mathrm{CH}_{3}\right)$. The presence of the hydroxyl $(-\mathrm{OH})$ group is likely to have originated from the $-\mathrm{OH}$ bond existing inside the oMMT nanofiller molecule and bonded to the nanoparticle/silicate layers surfaces by hydrogen bonding.

Likewise, the addition of oMMT nanofillers in the silicone rubber matrices increased the $-\mathrm{OH}$ functional groups results in the spectra band between $3650 \mathrm{~cm}^{-1}$ and $3500 \mathrm{~cm}^{-1}$, which indicates the free $-\mathrm{OH}$ stretching vibration in Figure 6(b). By adding $1 \mathrm{wt} \%$ and $3 \mathrm{wt} \%$ oMMT nanofiller, the $-\mathrm{OH}$ bands broadened significantly due to the abundance of $-\mathrm{OH}$ groups. The hydroxyl groups on the surface of the nanoparticles led to the formation of hydrogen bonds between the hydroxyl groups $(-\mathrm{OH})$ and the oxygen in the siloxane, which is the backbone of silicone rubber (PDMS) matrix.

This interpretation agrees with the studies done by Fragiadakis and Pissis [50] and Ramirez et al. [51] that dealt with the hydrogen bonding between silica/PDMS filler/polymer and the separation studies done by Singha and Thomas [52] and Nelson et al. [53] that explained the influence of the hydrogen bond due to the presence of the hydroxyl functional groups at the surfaces of untreated $\mathrm{ZnO}$ and $\mathrm{TiO}_{2}$ added to epoxy resin. These hydrogen bonds form the strong bond and tightly bounded layers at the interfaces between the nanoparticle and the silicone rubber matrix, as depicted in Figure 8.

In addition, the thermal stability of silicone rubber nanocomposites has also improved due to the ability to resist dehydration at high temperature by the presence of a high number of hydroxyl $(-\mathrm{OH})$ groups at the nanoparticle surfaces. Dehydration may result in weaker filler-polymer matrix interfaces. The presence of a high number of hydroxyl groups helps in hydration and removes the heat to lower the temperature at the interface, improving the insulation properties [51, 54].

The broad peak that appears at $\sim 1000-1200 \mathrm{~cm}^{-1}$ corresponds to $\mathrm{Si}-\mathrm{O}-\mathrm{Si}$ stretching, which may be due to an increase in the oxidative cross-linking reaction resulting from oxidation of the hydrocarbon groups on the polymer main chain. This reaction would lead to cross-linking and increase the network chain concentration, leading to a brittle (hard) surface layer $[55,56]$. In addition, the FTIR shows an increase in the number of hydrocarbon methyl $\left(\mathrm{CH}_{3}\right)$ groups with increasing filler concentration. The bands at $2975-2875 \mathrm{~cm}^{-1}$ correspond to the stretching vibration of the hydrocarbon methyl group. The transmittance amplitude also increased with the increase in filler content, which shows an increase in the alkyl groups. Therefore, the increase in filler concentration contributes to the increase in cross-link numbers of silicone rubber.

Sylgard 184 silicone rubber has a thermal stability between $-45^{\circ} \mathrm{C}$ and $200^{\circ} \mathrm{C}$ [57]. This excellent thermal stability is attributable to the high dissociation energy of the siloxane bond, $\mathrm{Si}-\mathrm{O}-\mathrm{Si}$, which is highly stable at a value of $445 \mathrm{~kJ} / \mathrm{mol}$ [58]. However, the influence of temperature on the number of cross-links could be elucidated by referring to the following formula [35]:

$$
E_{m}=\frac{3 \chi R T}{M_{a v}}
$$

where $E_{m}$ is the elastic modulus, $\chi$ is the density of silicone rubber, $R$ is the gas constant, $T$ is temperature, and $M_{a v}$ is the average molecular weight per vulcanization point in silicone rubber. The elastic modulus $E$ increases with the decrease in average molecular weight $M_{a v}$. The decrease in $M_{a v}$ results in an increase in the vulcanization point in silicone rubber. Thus, the increase in temperature $T$ increases the elastic modulus $E_{m}$ and thereby increases the vulcanization point density. The higher the elastic modulus, the stronger the forces that are required for material deformation. Therefore, the electrical tree becomes more difficult to propagate due to the increase in the elastic modulus as a function of temperature. The increase in $E_{m}$ increased the number of molecular bonds due to the increase in vulcanization points or number of cross-links that are required to be broken down to form more coalesced cavities for electrical tree initiation and propagation.

As a result, the resistance of the electrical tree and PD caused by increasing vulcanization or cross-link numbers is due to the influence of temperature. The existence of the hydrogen bond between the nanoparticle surfaces and silicone rubber matrices has led to the existence of better adhesion at the filler/polymer interface, which requires higher dissociation energy to break the bonding for polymer decomposition. However, in the case of silicone rubberbased nanocomposites (1 $\mathrm{wt} \%$ and $3 \mathrm{wt} \%$ ), the difference in $\mathrm{PD}$ and electrical tree resistivity is due to a decrease in interfiller distance, which implies a better shielding effect of the nanoparticles by leaving very narrow regions of the material (silicone rubber) exposed to the discharges. The nanoparticles may form a physical barrier against the discharges and lead to the enormous increase in the discharge resistance performance. With an increase in temperature, the best $\mathrm{PD}$ and electrical tree resistance/inhibition performance was exhibited by the silicone rubber-based nanocomposite 
(3 wt\%) taking into account all inhibition factors as discussed earlier.

\section{Conclusions}

The effect of temperature on electrical tree growth and corresponding PD activity were investigated in silicone rubber with different levels of oMMT nanofiller content. The presence of nanofiller reduced the temperature dependence of the electrical properties of the silicone rubber matrix such that the phase distribution of PD activities became insensitive to changes in temperature. The introduction of $3 \mathrm{wt} \%$ oMMT nanofiller inhibited electrical tree initiation over the temperature range with a 4-hour interval for each experiment. Under high temperature, the vulcanization effect played a role in introducing more cross-linking in the silicone rubber chains. Therefore, under a high temperature up to $60^{\circ} \mathrm{C}$, electrical treeing took more time to propagate at roomtemperature vulcanized silicone rubber. The presence of a hydroxyl group at the surface of nanoparticles led to the formation of hydrogen bonds between the hydroxyl and the oxygen from the siloxane backbone of the silicone rubber matrix. The hydrogen bond helped in strengthening the interaction between the nanoparticles and the polymer matrix thus increased the physical bonding. This enhanced bonding increased the insulation properties, thereby resisting PD and electrical tree degradation. As a result, this study suggests that oMMT nanoclay as a nanofiller could be employed in insulating materials to improve their degradation due to internal discharges.

\section{Conflict of Interests}

The authors declare no conflict of interests.

\section{Acknowledgments}

The authors wish to thank Universiti Teknologi Malaysia and Ministry of Education for financial support through research Grants Vot nos. 01K07, 4F599, 4F398, and 06H77. Last but not least, special thanks are due to Professor Dr. John Fothergill from City University, UK, Dr. Steve Dodd, and Dr. Nikola Chalashkanov from University of Leicester, UK, for their kind contributions and help during the study.

\section{References}

[1] S. S. Bamji, "Electroluminescence-a technique to detect the initiation of degradation in polymeric insulation," IEEE Electrical Insulation Magazine, vol. 15, no. 3, pp. 6-18, 1999.

[2] R. Sarathi and P. G. Raju, "Study of electrical treeing phenomena in XLPE cable samples using acoustic techniques," Electric Power Systems Research, vol. 73, no. 2, pp. 159-168, 2005.

[3] M. Bao, X. Yin, and J. He, "Analysis of electrical tree propagation in XLPE power cable insulation," Physica B: Condensed Matter, vol. 406, no. 8, pp. 1556-1560, 2011.

[4] X. Zheng and G. Chen, "Propagation mechanism of electrical tree in XLPE cable insulation by investigating a double electrical tree structure," IEEE Transactions on Dielectrics and Electrical Insulation, vol. 15, no. 3, pp. 800-807, 2008.

[5] L. Ying and C. Xiaolong, "A novel method for the insulation thickness design of HV XLPE cable based on electrical treeing tests," IEEE Transactions on Dielectrics and Electrical Insulation, vol. 21, no. 4, pp. 1540-1546, 2014.

[6] L. Ying and C. Xiaolong, "Electrical tree initiation in XLPE cable insulation by application of DC and impulse voltage," IEEE Transactions on Dielectrics and Electrical Insulation, vol. 20, no. 5, pp. 1691-1698, 2013.

[7] E. M. Jarvid, A. B. Johansson, J. H. M. Blennow, M. R. Andersson, and S. M. Gubanski, "Evaluation of the performance of several object types for electrical treeing experiments," IEEE Transactions on Dielectrics and Electrical Insulation, vol. 20, no. 5, pp. 1712-1719, 2013.

[8] J. K. Nelson, Dielectric Polymer Nanocomposites, Springer, Boston, Mass, USA, 2010.

[9] X. Huang, F. Liu, P. Jiang, and T. Tanaka, "Is graphene oxide an insulating material?" in Proceedings of the IEEE International Conference on Solid Dielectrics (ICSD '13), pp. 904-907, July 2013.

[10] W. A. Izzati, Y. Z. Arief, Z. Adzis, and M. Shafanizam, "Partial discharge characteristics of polymer nanocomposite materials in electrical insulation: A review of sample preparation techniques, analysis methods, potential applications, and future trends," The Scientific World Journal, vol. 2014, Article ID 735070, 14 pages, 2014.

[11] F. Guastavino, A. Dardano, S. Squarcia et al., "Electrical treeing in LDPE nanocomposite materials," in Proceedings of the 2009 IEEE Conference on Electrical Insulation and Dielectric Phenomena, pp. 697-700, June 2009.

[12] F. Guastavino, A. Dardano, G. C. Montanari, L. Testa, and F. Bellucci, "Electrical treeing in EVA-boehmite and EVAmontmorillonite nanocomposites," in Proceedings of the IEEE Electrical Insulation Conference (EIC '09), pp. 382-386, IEEE, Montreal, Canada, June 2009.

[13] Z. Jinmei, G. Junguo, J. Quanquan, Z. Mingyan, and Z. Xiaohong, "Studies on electrical tree and partial discharge properties of PE/MMT nanocomposites," in Proceedings of the International Symposium on Electrical Insulating Materials (ISEIM '08), pp. 311-314, September 2008.

[14] S. Raetzke, Y. Ohki, T. Imai, T. Tanaka, and J. Kindersberger, "Tree initiation characteristics of epoxy resin and epoxy/clay nanocomoposite," IEEE Transactions on Dielectrics and Electrical Insulation, vol. 16, no. 5, pp. 1473-1480, 2009.

[15] B. X. Du, Z. L. M. Gao, and T. Han, "Effect of temperature on electrical tree in silicone rubber," in Proceedings of the 10th IEEE International Conference on Solid Dielectrics, pp. 1-4, 2010.

[16] H. G. Yaworski, G. Craig, and D. Roberts, "The use of silicon gels for jointing power cables," in Proceedings of the 14th IEEE Transmission and Distribution Conference, pp. 396-401, September 1996.

[17] R. R. Bukovnik and P. R. Carey, "Advances in silicone gel technology for cable accessories," in Proceedings of the IEEE Power Engineering Society Transmission and Distribution Conference, pp. 634-637, Dallas, Tex, USA, May 2006.

[18] H. G. Yaworski and R. R. Bukovnik, "Silicone gel technology for power cable accessories," in Proceedings of the IEEE/PES Transmission and Distribution Conference and Exposition, vol. 2, pp. 837-842, November 2001.

[19] A. A. A. Jamil, M. Kamarol, M. Mariatti et al., "Organomontmorillonite as an electrical treeing retardant for polymeric 
insulating materials," in Proceedings of the IEEE International Conference on Condition Monitoring and Diagnosis (CMD '12), pp. 237-240, September 2012.

[20] B. X. Du, Z. L. Ma, Y. Gao, T. Han, and Y. S. Xia, "Effects of nano filler on treeing phenomena of silicone rubber nanocomposites," in Proceedings of the Annual Report Conference on Electrical Insulation and Dielectric Phenomena (CEIDP '11), pp. 788-791, October 2011.

[21] M. Arroyo, M. A. López-Manchado, and B. Herrero, "Organomontmorillonite as substitute of carbon black in natural rubber compounds," Polymer, vol. 44, no. 8, pp. 2447-2453, 2003.

[22] A. A. A. Jamil, N. Bashir, M. H. Ahmad, Y. Z. Arief, M. Kamarol, and M. Mariatti, "Electrical treeing initiation and propagation in silicone rubber nanocomposites," in Proceedings of the IEEE Conference on Electrical Insulation and Dielectric Phenomena (CEIDP '13), pp. 502-505, IEEE, Shenzhen, China, October 2013.

[23] R. Liao, G. Bai, L. Yang, H. Cheng, Y. Yuan, and J. Guan, "Improved electric strength and space charge characterization in LDPE composites with montmorillonite fillers," Journal of Nanomaterials, vol. 2013, Article ID 712543, 7 pages, 2013.

[24] R. Jongen, E. Gulski, and J. Smit, "Failures of medium voltage cable joints in relation to the ambient temperature," in Proceedings of the 20th International Conference and Exhibition on Electricity Distribution (CIRED '09), 11, p. 8, June 2009.

[25] N. Shimizu, Y. Shibata, K. Ito, K. Imai, and M. Nawata, "Electrical tree at high temperature in XLPE and effect of oxygen," in Proceedings of the IEEE Conference on Electrical Insulation and Dielectric Phenomena, vol. 1, pp. 329-332, October 2000.

[26] J. Kindersberg, A. Scutz, H. Karner, and R. Huir, "Service performance, material design and applications of composite insulators with silicone rubber housings," CIGRE 33-303, 1996.

[27] F. Bellucci, D. Fabiani, G. C. Montanari, and L. Testa, "The processing of nanocomposites," in Dielectric Polymer Nanocomposites, J. K. Nelson, Ed., pp. 31-64, Springer, Boston, Mass, USA, 2010.

[28] Y. Kojima, A. Usuki, M. Kawasumi, A. Okada, T. Kurauchi, and O. Kamigaito, "One-pot synthesis of nylon 6-clay hybrid," Journal of Polymer Science Part A: Polymer Chemistry, vol. 31, no. 7, pp. 1755-1758, 1993.

[29] M. Alexandre and P. Dubois, "Polymer-layered silicate nanocomposites: preparation, properties and uses of a new class of materials," Materials Science and Engineering R: Reports, vol. 28, no. 1, pp. 1-63, 2000.

[30] S. Sinha Ray, K. Okamoto, and M. Okamoto, "Structureproperty relationship in biodegradable poly(butylene succinate)/layered silicate nanocomposites," Macromolecules, vol. 36, no. 7, pp. 2355-2367, 2003.

[31] A. A. A. Jamil, M. H. B. Ahmad, M. Kamarol, M. Mariatti, and M. A. M. Piah, "Short-term breakdown in silicone rubber based nanocomposites caused by electrical treeing," Advanced Materials Research, vol. 845, pp. 482-486, 2013.

[32] I. A. Tsekmes, Electrical characterization of polymeric DC mini-cables by means of space charge \& conduction current measurements [BEng thesis], Delft University of Technology, 2012.

[33] K. Ishimoto, E. Kanegae, Y. Ohki et al., "Superiority of dielectric properties of LDPE/MgO nanocomposites over microcomposites," IEEE Transactions on Dielectrics and Electrical Insulation, vol. 16, no. 6, pp. 1735-1742, 2009.

[34] N. M. Chalashkanov, S. J. Dodd, L. A. Dissado, and J. C. Fothergill, "Pulse sequence analysis on PD data from electrical trees in flexible epoxy resins," in Proceedings of the Annual Report Conference on Electrical Insulation and Dielectric Phenomena (CEIDP '11), pp. 776-779, October 2011.

[35] B. X. Du, Z. L. Ma, Y. Gao, and T. Han, "Effect of ambient temperature on electrical treeing characteristics in silicone rubber," IEEE Transactions on Dielectrics and Electrical Insulation, vol. 18, no. 2, pp. 401-407, 2011.

[36] M. G. Danikas and T. Tanaka, "Nanocomposites-a review of electrical treeing and breakdown," IEEE Electrical Insulation Magazine, vol. 25, no. 4, pp. 19-25, 2009.

[37] T. Tanaka, "Internal partial discharge and material degradation," IEEE Transactions on Electrical Insulation, vol. 21, no. 6, pp. 899-905, 1986.

[38] M. G. Danikas, "Small partial discharges and their role in insulation deterioration," IEEE Transactions on Dielectrics and Electrical Insulation, vol. 4, no. 6, pp. 863-867, 1997.

[39] M. G. Danikas, "The definitions used for partial discharge phenomena," IEEE Transactions on Electrical Insulation, vol. 28, no. 6, pp. 1075-1081, 1993.

[40] T. Tanaka, "Partial discharge pulse distribution pattern analysis," IEE Proceedings: Science, Measurement and Technology, vol. 142, no. 1, pp. 46-50, 1995.

[41] T. Takahashi, J. Suzuki, H. Miyata et al., "Relation between electroluminescence and degradation in XLPE," IEEE Transactions on Dielectrics and Electrical Insulation, vol. 8, no. 1, pp. 91-96, 2001.

[42] S. Alapati and M. J. Thomas, "Electrical treeing and the associated PD characteristics in LDPE nanocomposites," IEEE Transactions on Dielectrics and Electrical Insulation, vol. 19, no. 2, pp. 697-704, 2012.

[43] R. Kurnianto, Y. Murakami, N. Hozumi, and M. Nagao, "Characterization of tree growth in inorganic-filler/epoxy resin composite material," in Proceedings of the 8th International Conference on Properties and Applications of Dielectric Materials (ICPADM '06), pp. 123-126, June 2006.

[44] M. Nagao, K. Oda, K. Nishioka, Y. Muramoto, and N. Hozumi, "Effect of filler on treeing phenomenon in epoxy resin under AC voltage," in Proceedings of the International Symposium on Electrical Insulating Materials (ISEIM '01), pp. 611-614, IEEE, Himeji, Japan, 2001.

[45] J. P. Reynders, I. R. Jandrell, and S. M. Reynders, "Review of aging and recovery of silicone rubber insulation for outdoor use," IEEE Transactions on Dielectrics and Electrical Insulation, vol. 6 , no. 5, pp. 620-631, 1999.

[46] G. W. Gokel, Dean's Handbook of Organic Chemistry, McGrawHill, 2nd edition, 2004.

[47] S. Ganga, G. R. Viswanath, and R. S. S. Aradhya, "Improved performance of silicone rubber insulation with nano fillers," in Proceedings of the IEEE 10th International Conference on the Properties and Applications of Dielectric Materials (ICPADM '12), pp. 1-4, IEEE, Bangalore, India, July 2012.

[48] S.-H. Kim, E. A. Cherney, R. Hackam, and K. G. Rutherford, "Chemical changes at the surface of RTV silicone rubber coatings on insulators during dry-band arcing," IEEE Transactions on Dielectrics and Electrical Insulation, vol. 1, no. 1, pp. 106-123, 1994.

[49] C. Lee, K. J. K. Lim, Y. G. Y. Park, B. H. Ryu, and K. Y. Kim, "Radiation effects on electrical treeing resistance and mechanical characteristics of low density polyethylene containing barbituric acid derivatives," in Proceedings of the 6th International Conference on Properties and Applications of 
Dielectric Materials, vol. 1 of (Cat. No. 00CH36347), pp. 501-504, 2000.

[50] D. Fragiadakis and P. Pissis, "Glass transition and segmental dynamics in poly(dimethylsiloxane)/silica nanocomposites studied by various techniques," Journal of Non-Crystalline Solids, vol. 353, no. 47-51, pp. 4344-4352, 2007.

[51] I. Ramirez, S. Jayaram, E. A. Cherney, M. Gauthier, and L. Simon, "Erosion resistance and mechanical properties of silicone nanocomposite insulation," IEEE Transactions on Dielectrics and Electrical Insulation, vol. 16, no. 1, pp. 52-59, 2009.

[52] S. Singha and M. J. Thomas, "Influence of filler loading on dielectric properties of epoxy-Zno nanocomposites," IEEE Transactions on Dielectrics and Electrical Insulation, vol. 16, no. 2, pp. 531-542, 2009.

[53] J. K. Nelson, L. A. Utracki, R. K. MacCrone, and C. W. Reed, "Role of the Interface in determining the dielectric properties of nanocomposites," in Proceedings of the 17th Annual Meeting of the IEEE Lasers and Electro-Optics Society (LEOS '04), pp. 314317, October 2004.

[54] B. Venkatesulu and M. J. Thomas, "Erosion resistance of alumina-filled silicone rubber nanocomposites," IEEE Transactions on Dielectrics and Electrical Insulation, vol. 17, no. 2, pp. 615-624, 2010.

[55] B. Ma, J. Andersson, and S. M. Gubanski, "Evaluating resistance of polymeric materials for outdoor applications to corona and ozone," IEEE Transactions on Dielectrics and Electrical Insulation, vol. 17, no. 2, pp. 555-565, 2010.

[56] D. K. Thomas, "Network scission processes in peroxide cured methylvinyl silicone rubber," Polymer, vol. 7, no. 2, pp. 99-105, 1966.

[57] Dow Corning, Solar Sylgard 184 Silicone Elastomer Data Sheet.

[58] A. E. Beezer and C. T. Mortimer, "Heats of formation and bond energies. Part XV. Chlorotrimethylsilane and hexamethyldisilazane," Journal of the Chemical Society A: Inorganic, Physical, Theoretical, pp. 514-516, 1966. 

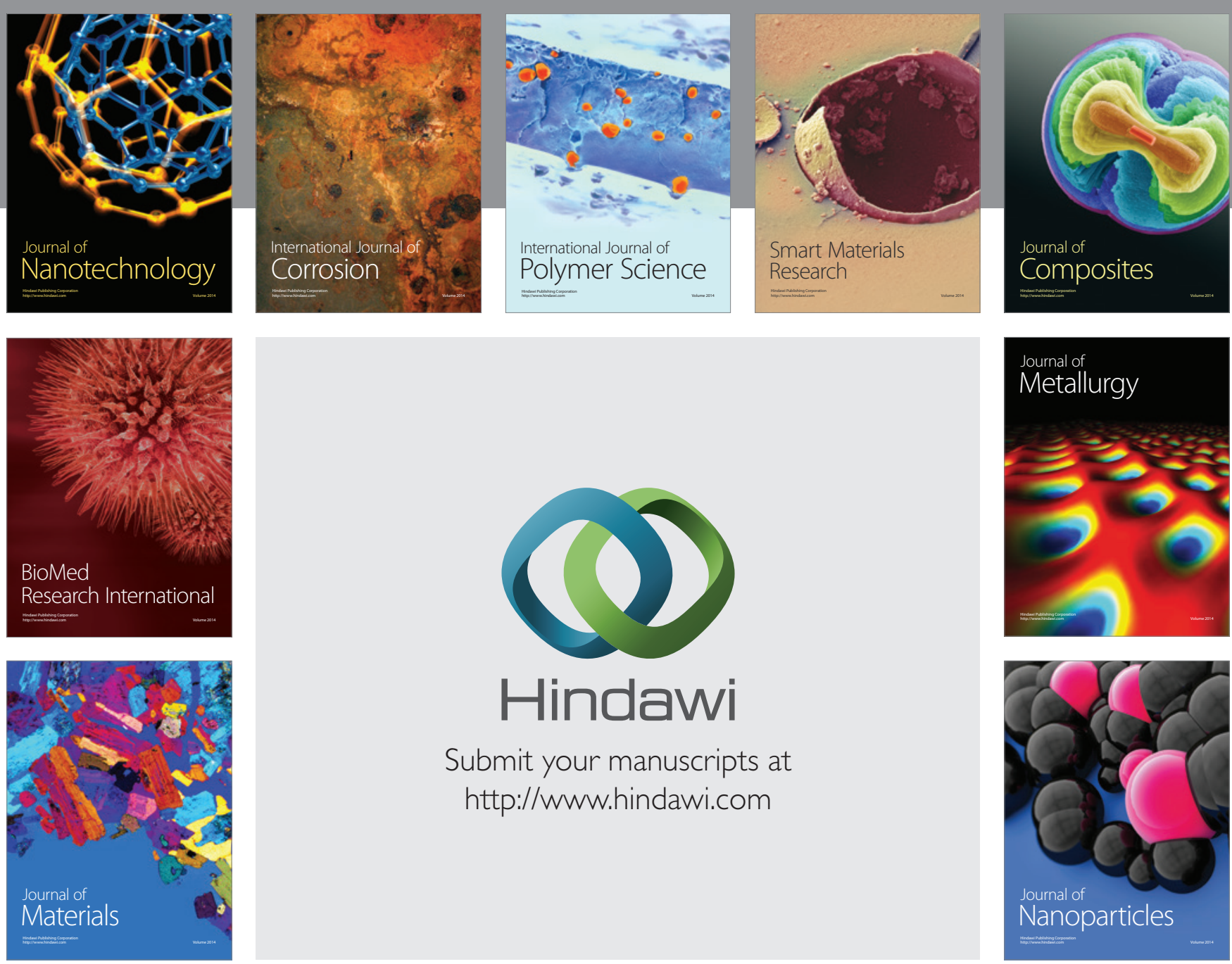

Submit your manuscripts at http://www.hindawi.com
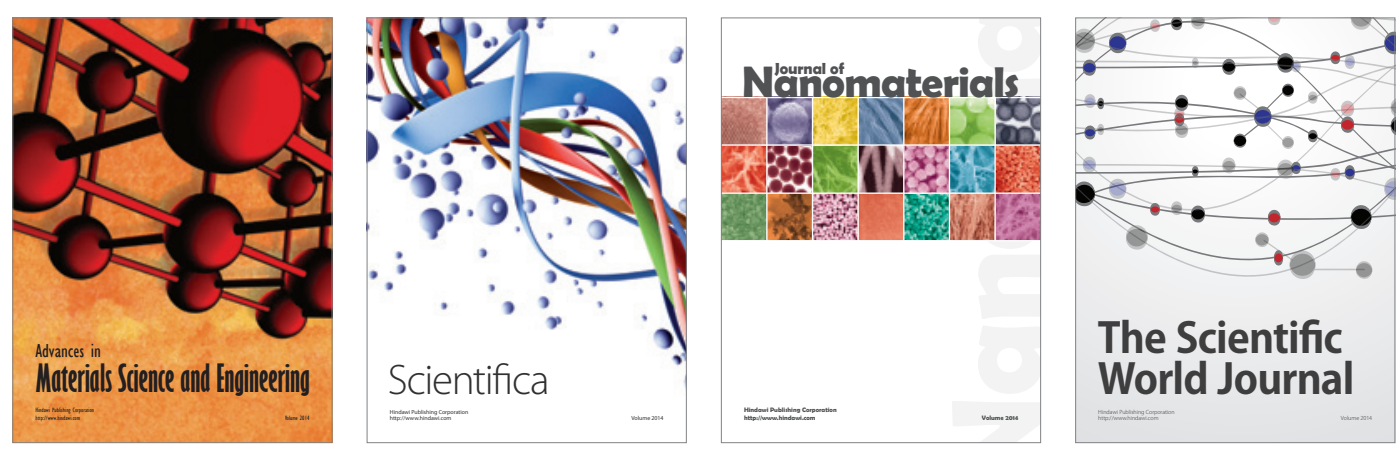

\section{The Scientific World Journal}
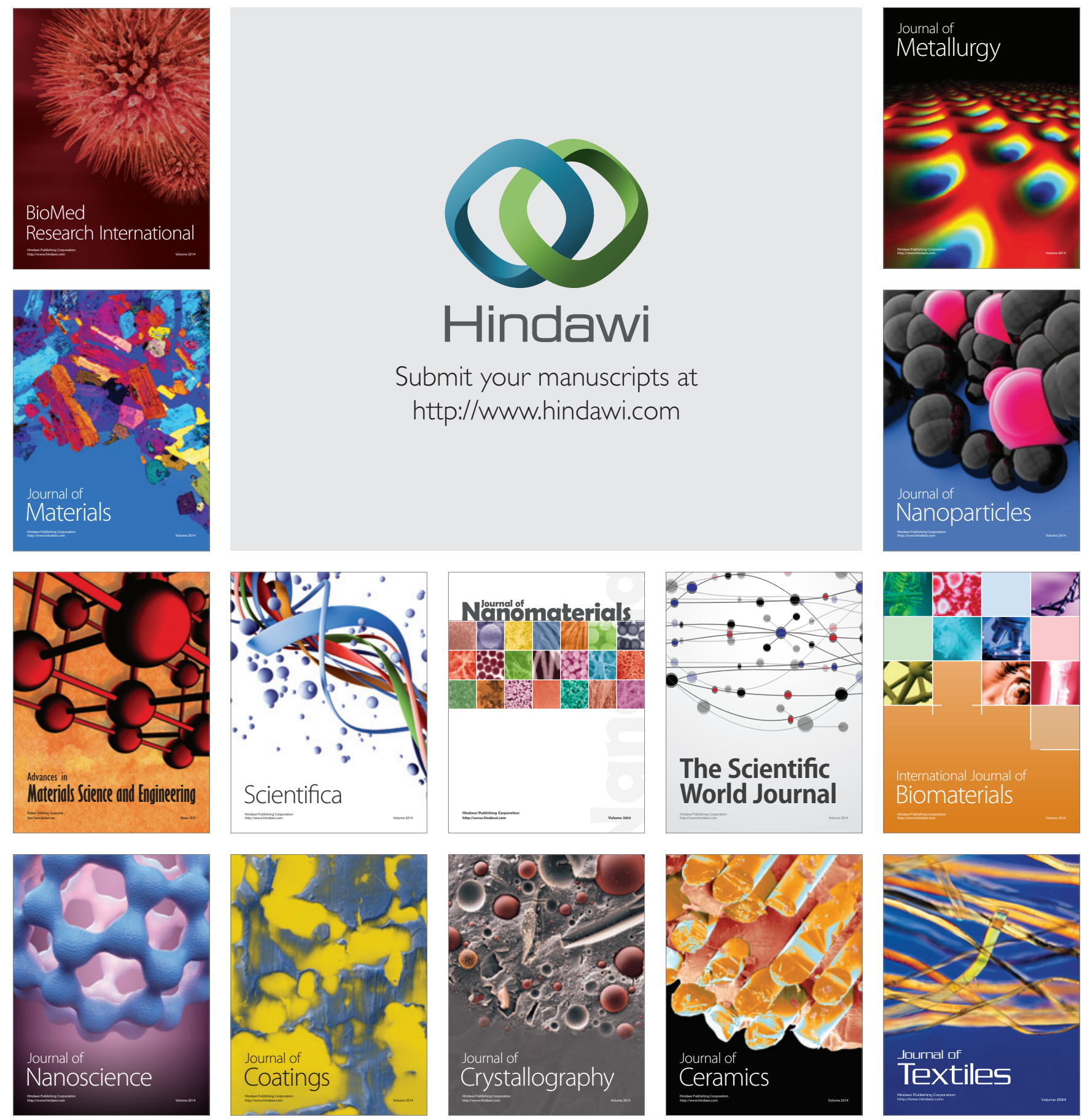